\title{
Crossing Boundaries Creating Community College Partnerships to Promote Educational Transitions
}

\author{
Marilyn J. Amey \\ Michigan State University \\ Pamela L. Eddy \\ College of William \& Mary, pamela.eddy@wm.edu \\ Timothy G. Campbell \\ Central Michigan University
}

Follow this and additional works at: https://scholarworks.wm.edu/articles

Part of the Community College Leadership Commons, and the Educational Leadership Commons

\section{Recommended Citation}

Amey, Marilyn J.; Eddy, Pamela L.; and Campbell, Timothy G., "Crossing Boundaries Creating Community College Partnerships to Promote Educational Transitions" (2010). Articles. 61.

https://scholarworks.wm.edu/articles/61

This Article is brought to you for free and open access by W\&M ScholarWorks. It has been accepted for inclusion in Articles by an authorized administrator of W\&M ScholarWorks. For more information, please contact scholarworks@wm.edu. 
Crossing Boundaries: Creating Partnerships to Promote Educational Transitions

It is increasingly clear that economic growth and competitiveness requires an emphasis on education, skills and training of all state residents. For instance, in Michigan, the Cherry Commission Report (2004) directly reinforces this connection as it outlines goals of dramatically increasing access to higher education and training opportunities for citizens of Michigan with the goal of jump starting the state economy. Many states have drawn upon the Gaining Early Awareness and Readiness for Undergraduate Programs (GEAR UP) grant initiative to promote access to higher education, especially for under-represented students. State policy makers are likewise looking for ways to solve economic problems and are increasingly pushing for collaborations with an eye toward economies of scale and resource savings. Coupled with this, students need to prepare for a different and more demanding future labor market that includes a knowledge economy and global awareness. Collaborative partnerships across organizations are important and strategic ways of meeting states' education and economic goals. When successful, they are good for the schools, community colleges, and universities involved, optimally use state and local resources, and provide greater access to meet student learning needs. Cross-level educational partnership goals vary depending on the impetus for initially creating the collaboration and these roots affect how partnerships evolve over time.

When innovation is important and resources are scarce, partnerships provide options beyond what schools and community colleges can accomplish individually, thereby, greatly benefiting institutional members; partnerships can enable greater educational access and opportunity for students, resulting in a greater public good, as well (Chin, Bell, Munby, \& Hutchinson, 2004). Initiatives can aid in achieving internal 
Crossing Boundaries: Creating Partnerships to Promote Educational Transitions

institutional goals, involve resource sharing with more efficiency (Russell \& Flynn, 2000), meet technology demands (Sink, Jackson, Boham, \& Shockley, 2004), and provide better service delivery (Bragg, 2000). Traditional articulation and dual enrollment/credit agreements, for example, provide more streamlined access to postsecondary education for many high school students and are considered beneficial to both postsecondary institutions and public schools (Bragg \& Russman, 2007; Farrell \& Seifert, 2007; Rasch, 2002). Dual enrollment, accelerated programs degree programs, and even three-year college degrees are increasingly a part of conversations looking for ways to fast track students to degree completion and into the labor market (Keller, 2008).

Yet, it is not enough to mandate these partnerships at state or federal levels and expect immediate or positive results since the goals may not be seen as beneficial to all, rather are seen by the players as a form of compliance. Nor should we assume that educational institutions can easily collaborate simply because they are publicly funded and have student learning as a primary mission. Partnerships are sometimes considered "fringe activities," risky, difficult to negotiate, political, and easily challenged by the institutional status quo (Bruffee, 1999; Fear, Creamer, Pirog, Block, \& Redmond, 2004). Despite perceived initial benefits, partnerships are often difficult and almost always more complicated than at first appears. Many partnerships fail to obtain desired results, cannot be sustained for long periods of time, or cease to benefit both parties (Eddy, 2007; Fear, et al.). They rarely truly succeed if created by fiat and mandate (Eddy; Farrell \& Seifert, 2007), even if they have great potential to accomplish increased access and learning opportunities. Thus, it is important to investigate the underlying operations involved in 
Crossing Boundaries: Creating Partnerships to Promote Educational Transitions

partnerships, how these cooperatives get established, and what helps them succeed (or not).

Two important points underlie our argument. First, partnerships can be useful in achieving sound educational outcomes and can be of benefit to each organization involved and to students. Second, they are often difficult to establish and sustain because of fundamental differences between educational organizations. At the same time, it is possible to construct strategic alliances between community colleges, public schools and universities that appropriately address state education needs when we understand the essential components of partnerships stimulated by public policies and the challenges faced when engaging in these activities.

For the institutions involved, benefits come from facilities sharing including classroom, laboratory and computer equipment, and athletic facilities that make more efficient use of existing physical plant and may stave off new purchases or construction during difficult local economic times (Brumbach \& Villadsen, 2002; Keener, Carrier, \& Meaders, 2002). Pooling institutional resources for purchasing or construction may provide better results than what schools or colleges can independently afford. Optimally, each partner has to see why they need and want to be involved, and how partnership benefits the member institutions. The ways community colleges and the organizations with which they partner benefit need not be the same, and often are not, but it is easy for power and rewards to become unevenly distributed as a result. Sometimes this is addressed by having commonly understood and not just shared goals.

For students, partnerships across educational sectors can help ease transitions from K-12 to postsecondary education (Bragg, 2000), which is essential to increased 
education for all citizens as noted in initiatives such as Achieving the Dream (Hart, 2009; Lincoln, 2009). Educators working together across institutional levels can provide smooth pathways and options for students who have been historically disabled by the traditional systems and structures, find creative options, support networks, address diverse learning needs, and identify alternative strategies that assist all students in their pursuit of educational goals. All of these objectives, historically part of the overall mission of community colleges on behalf of students, require effective partnerships with schools and other institutions. Advanced Placement [AP] and on-line course offerings, clear credit transfer processes, improved communication about college expectations to current high school students, consistency in K-12 requirements that change the nature and success of prospective college learners, enrichment programs for high school students on community college campuses, and more cooperative strategies for addressing developmental learners are just some examples of the range of cross-level collaborations that increase opportunities for the full range of learners and future laborers.

For states, collaborations provide needed opportunities for professional development and training for educators and other adult learners, often on-site or through on-line learning that is important to innovation and keeping pace in the global knowledge environment (Levin, 2002). Indeed, President Obama's recent announcement to funnel $\$ 12$ Billion in federal funding to community colleges (Shear \& de Vise, 2009) underscores the focus on the transfer function of community colleges and the use of education as a lever to economic recovery (Lumina Foundation, 2009). Partnerships may also reduce resource redundancy and increase effective use of state fiscal, physical and personnel resources. Policy makers are often interested in using partnerships to leverage 
Crossing Boundaries: Creating Partnerships to Promote Educational Transitions

change that is not obtainable on a single institutional level, especially when looking across public sector institutions or educational sectors. It seems that bringing educators together can create great synergy and opportunities for change than is sometimes true for single institutions.

In order to more fully understand community college collaborations, how and why they function, and whether or not there are lessons common to them that can be used strategically, it is important to look past the "value-added" rhetoric found with most calls for educational alliances, and ask questions that more closely examine aspects of partnerships. Our work studying educational partnerships in several states over the last three years has shown the following are important questions in extracting meaning, relevance, and utility of educational partnerships: What was the impetus to initiate the partnership? What is the context of the partnership? How is the partnership understood by others and what is the role of leadership in framing the partnership for constituents? What are the outcomes, benefits and costs of the partnership? What is required to sustain the partnership or to let is dissolve?

\section{Partnership Model}

In this section, we present a partnership model that reflects critical elements we found after consultation with an expert community college advisory panel and reviewing K-14 partnerships in our own state and nationally. This research provides leaders with a better way to understand the implications of policies on educational practices, particularly noting key levers of change and potential trouble spots.

\section{Stage One: Getting Started}


Crossing Boundaries: Creating Partnerships to Promote Educational Transitions

The questions posed above provided the foundation to consider the essential elements in the creation of a three phase partnership model. The first phase in the model includes the antecedents for each of the partners that contribute to the reason for initiating or joining an existing partnership (see Figure 1). Antecedents include, but are not limited to, individual partners' resources, motivations for partnering, policy context, and existing relationships. As noted, partners come together for different reasons, some of which may be voluntary and similar, while others are mandated and disparate. In addition to the initial motivator(s), we also found that, for various reasons, members of partnerships may have more or less social and organizational capital at their disposal, which adds dynamic features to understanding partnerships (Hoffman-Johnson, 2007; Kisker \& Hauser, 2007; Watson, 2007). Regardless of how formal the arrangement, roles and responsibilities of partners need to be clear.

\section{[Insert Figure 1 About Here]}

Social capital is an intangible resource for productive ends inherent in social relationships and structures. As a phenomenon, social capital was first identified in the sociological literature but is also familiar in organizational behavior circles. Although definitions may vary somewhat, social capital typically is represented with two commonalties: it is connected to social structure, and it facilitates certain actions of actors, whether persons or corporate actors, within the organization or partnership (Coleman, 1988). Unlike other forms of capital, social capital exists in the structure of relationships and networks between and among actors (Adler \& Kwon, 2002; Coleman; Morgan, 1998; Scott, 2003). It includes such components as trust, closeness, amount of 
Crossing Boundaries: Creating Partnerships to Promote Educational Transitions

interaction, personal power, respect, commitment, and integrity (Bryk \& Schneider, 2002; Coleman; Granovetter, 1983).

Density, centrality, and trust as aspects of social capital affect partnerships, and the extent of relationship networks helps determine the range of opportunities for developing and activating one's social capital on behalf of partnerships (Adler \& Kwon, 2002; Coleman, 1988; Scott, 2003). Density refers to the strength and closeness of relationships (Adler \& Kwon; Granovetter, 1983). High levels of density relate to trust. The more trust at the beginning of the relationship, and often throughout, results in partners likely to be more flexible with one another, leading to persistence through difficult times within the collaboration. Density is also liable to be important in developing norms and mutual expectations in that having close and strong relationships typically requires enough interaction between parties to establish and maintain norms and levels of trust. Those who share strong ties tend to see each other as more credible and trusted sources of information (or other resources). Centrality relates to the extent to which a person is central to the overall structure of the partnership (Adler \& Kwon). This is not an individual attribute but a function of the structure of relationships and likely influenced by the culture of the organization. One's position in the social network affects how one is viewed as a leader. From a strategic perspective, stronger partnerships might be formed with individuals who are closer to the core functions of the alliance rather than those who may be very supportive of end goals but also far removed from central decision making or delivery systems. For instance, strong support from program directors is of little consequence if they do not control resources to aid the partnership or if decision making requires checking with several others prior to moving forward. Trust 
Crossing Boundaries: Creating Partnerships to Promote Educational Transitions

evolves over time and is based on the fostering of network relationships (Bryk \& Schneider, 2002). Stronger density among partners results in higher levels of trust.

Evidence of trust is apparent when partners are able to rely on one another, feel there is honesty and openness in the relationship, and see a level of competence and benevolence in their collaborators (Hoy \& Tschannen-Moran, 1999).

We also know that working relationships between individuals and groups are affected by organizational capital. Organizational capital refers to resources, power, influence, authority, communication systems, and other aspects of the organization upon which members can draw to facilitate or achieve particular partnership goals (Morgan, 1998; Scott, 2003; Smyth, 1989). Much like social capital, organizational capital is used to facilitate or achieve particular partnership goals for institutions. Unlike social capital, organizational capital is not limited to social structures and relationships though it may include them; rather, it takes many forms ranging from cultural capital to formal structures and tangible resources (Morgan; Scott; Smyth).

We assume that organizational capital is unevenly distributed and that it is subject to change (Fullan; 2001; Kotter, 1996; Scott, 2003; Weick, 2001). Furthermore, the resources, power, influence, authority, communication systems and other aspects of the organization that individuals or a collective can draw on are unevenly distributed and may change over time (Fullan; Kotter; Scott; Weick). Organizational capital may accrue or be tied to formal position or may be a function of other less tangible aspects of the organization such as years of institutional experience, expertise, control of resources, and networks. For various reasons, members of partnerships may be more or less able to use their social and organizational capital at any given point (Hoffman-Johnson, 2007; 
Crossing Boundaries: Creating Partnerships to Promote Educational Transitions

Watson, 2007), thereby adding a very dynamic feature to understanding how partnerships develop and are sustained or ended.

Social and organizational capital are critical at the beginning of the partnership (Todeva \& Knoke, 2005). Who you know can serve as the impetus and starting point for collaboration. Individual and institutional reputations as forms of social capital are also important for building trust early in the partnership. Factors such as available resources, trustworthiness for follow through, and genuineness of mission and goals impact whether prospective partners want to come together in collaborative arrangements and are assessed on some level before even entering into relationships (Chung, Singh, \& Lee, 2000). It may be easier to consider the nature of social and organizational capital when potential partners already know each other at least by reputation and not as easy when partnerships are mandated by external agencies, including state or federal policies or mandates. In these cases, and in others constructed of less voluntary partners, motivation and a willingness to trust in potentially risky initiatives may be inhibited. The amount of social or organizational capital that individuals have within negotiated relationships, including educational partnerships, influences how supported they are by their own institutions, the level of tension and willingness to negotiate, and how informal or formal the collaboration will be (Gray, 1989).

The fact that partners have different reasons (motivations) for participating is not inherently problematic in educational collaborations even in early stages of partnership development as long as the arrangement is seen as mutually beneficial (Farrell \& Seifert, 2007). If benefits begin to accrue significantly more for one partner than another, motivations to participate can change (Eddy, 2007). Those with less pressing or more 
tangential motivations tend to fall away from involvement in the partnership, become less active, or bow out altogether. Conversely, those with greater motivation to participate may over-invest without necessarily reaping comparable benefits (Hoffman-Johnson, 2007). Key to the model, and partnership success, is how the institution and its members frame the partnership and how the perspective changes as the partnership continues. In every community college collaboration members need to understand the motivation behind and benefits of the partnership. Effective and consistent communication helps establish the context, clarifies goals and objectives, and creates common vocabulary and understandings (Eddy, 2003; Fairhurst \& Sarr, 1996).

\section{Stage Two: Partnership Development}

The second stage of the partnership model captures the processes involved in developing the collaboration beyond the self-interest of partners and begins to illustrate factors that contribute to or inhibit partnership evolution. Each individual partner has different intentions for involvement. In this case, shared meaning may occur on a macro level, but differences in intentionality or motivation may lead to conflict or lack of shared understanding at the micro, or implementation level. In the end, different intentions for participation may threaten the partnership. If intentions are not aligned well, each partner may need or expend more capital to sustain the partnership. Partners may not have the same status or authority in their institution, so relationships may be affected as the partnership evolves. Differences may also exist in each partner's resource base within their organization that is available for the partnership development. For example, a superintendent and community college president may have comparable resources to draw upon in developing an articulation agreement but a classroom teacher in a school and a 
Crossing Boundaries: Creating Partnerships to Promote Educational Transitions

faculty member in a community college may have to negotiate their resources differently when trying to implement that agreement because of differences in contractual relationships, control of time, and curriculum inherent in schools and universities.

A synergistic developmental process emerges. What often begins with a mandate (formal process) increasingly relies on trust (social process) as the partnership progresses and becomes more institutionalized. Accountability can be introduced if roles are established. Changes in members or responsibilities over time in longer term partnerships happen more easily because the process is more objective and less person-dependent. As trust between individuals within the partnership grows through interaction, the rigidity of a formal partnership contract gives way to a more informal and flexible working relationship that is more likely to weather the need for ongoing negotiation and changes over time (Todeva \& Knoke, 2005). Movement from formal to social processes depends on developing trust and as the partnership institutionalizes, increased reliance on trust and social capital contribute to flexibility and partnership "learning."

Another key element during the development stage is institutional comparability. When K-12 and community colleges try to work together, one consideration is the norms and culture of the faculty and K-12 staff who control the curriculum, the level of governing board involvement, and the organizational structure which may impact decision making. Thus, even though there may be agreed upon overarching goals, how each organization enacts the goals may be different. It is important to distinguish early on between short-term, situation-specific collaborations and those intended to be sustained. The differences in support, resource needs, buy-in, structure, and leadership can be dramatic. The more developed the partnership, the increased likelihood of weathering a 
Crossing Boundaries: Creating Partnerships to Promote Educational Transitions

crisis since the social capital (and trust that is a part of it) invested in relationships may ultimately sustain the partnership. The depth of relationships and subsequent trust may also provide bridges of understanding between somewhat different norms and aspects of culture that would otherwise undermine collective work. (See Figure 2).

\section{[[Insert Figure 2 About Here]]}

In addition to understanding the intentionality, status, power, resources, norms and expectations each partner brings to the relationship, it is important to remember that one or more of the partners are framing and communicating the meaning of the partnership and generating buy-in among members (Fairhurst \& Sarr, 1996). Whoever is playing this meaning-making role most clearly needs to establish a strong base of common understanding that creates a shared collective vocabulary and interpretation of events. On the other hand, varying interpretations (Morgan, 1998; Weick, 1995) often result in incoherence since partners bring different perspectives to the collaboration. It is not enough to explain things once and expect this will suffice as the partnership evolves. Leaders need to seize opportunities to celebrate partnership successes, to highlight and showcase effective examples, outcomes and strategies (Amey \& Brown, 2004; Morgan, 1998), e.g., agreement signing and ribbon-cutting ceremonies for new partnerships open to the public show the symbolic value of the collaborative work and invite constituents to feel part of the process from the beginning.

Another overarching factor in partnerships is the role of a champion. The champion is a person or group that advocates for the initiative (Kotter \& Cohen, 2002), and often believes in the goals of the partnership. The champion needs to have the support of the positional leader, but does not have to be in a particular position of 
traditional authority within the organization. More broadly conceived, the personal, organizational, and social capital that the champion maintains is often what contributes to success. At the same time, over-reliance on one champion can detract from institutionalizing the partnership and allowing it to become more broadly accepted by constituents. As with most features of academic organizations, those that continue over time become part of the culture and are built into administrative processes of the organization (e.g., its planning and budget cycles, reporting lines). This provides a greater degree of stability than the interpersonal dynamics associated with being too closely tied to single individuals within the organization.

\section{Stage Three: Incorporating the Partnerships}

Finally, the third stage of the partnership model involves creating partnership capital. We argue that partnership capital evolves and can be demonstrated when there are shared norms, shared beliefs, and networking that aligns processes among individual collaborators. Each arrangement may not result in partnership capital, but if the goal is to sustain the collaboration over time, we believe that understanding partnership capital, how it is formed, how it works, and its benefits and drawbacks to organizational collaboration may be a critical next step in cultivating effective partnerships. Partnership capital occurs at the intersection of the social and organizational capital shared by each collaborator, regardless of the level contributed. There is a synergy created at the nexus for partners; the whole is greater than the sum of the parts.

Partnership capital helps with institutionalization and serves as a basis for sustaining the collaboration. Even with partnership capital, not all partners contribute equally or consistently over time, resulting in the need to manage these capital 
differences with particular attention to partner intentions for the relationship. (See Figure 3). This section of the model shows that various levels of individual capital fluctuate, as represented by the difference in size of the circles in stage three. The connecting point for the individual partners is represented in the Venn diagram at the point of intersection of all the three circles. This common area is the location of the newly created partnership capital, consisting of shared norms, shared beliefs, and networking.

\section{[[Insert Figure 3 About Here]]}

As noted, attributes of each individual partner include power, rank or status, resources, and intentions. Since these factors differ by person and over time, the range and amount of partnership capital created is dependent on the individuals and their interactions. For example, a person may have high levels of individual power (Morgan, 1998), but smaller amounts of organizational power at their disposal at any given time that results in unequal contributions at any given time resulting in unequal contributions to the partnership. No matter the amount these individual partner qualities combine to create a new form of capital that potentially exists apart from individual players or specific organizational features/systems. Structural issues and inequities between partners often confound sustaining relationships, thus underscoring why developing partnership capital is so important. Several potential areas of tension follow that highlight the challenges of sustaining partnerships both from an individual level and an organizational perspective.

Teacher/faculty work structures and rewards. Even though both K-12 teachers and community college faculty value teaching and students, there are often significant differences in public school teachers' and community college faculty's work structures 
Crossing Boundaries: Creating Partnerships to Promote Educational Transitions

and rewards. Teaching loads, work hours, contract stipulations (or lack of contract), fulltime or part-time employment status, instructor identity and expertise are some distinctions that affect partnerships. Partnership involvement may be tangential to each educator's primary responsibilities and may have professional costs as much as benefits. How these activities are valued, included in work, and considered in reward structures are important to sustained involvement, especially because regular contact and meetings are consistently identified as keys to success. Partnership work is often hidden, extra, seen as service or being a good citizen, and does not always fit into typical evaluation criteria. If faculty members get no credit in annual evaluation or teachers can be involved only after the school day ends, partnering may be more professionally problematic than beneficial. Who assigns work, how commitment is maintained for longer periods of time, and how partnership activities get integrated into normal work assignments differ across organizations; so does whether one can take the initiative to partner or has to wait to be included.

Institutional policies and values. Many educational partnerships are challenged by very distinct organizational cultures, values, and institutional policies that conflict and are more complex than they appear or perhaps, than they should be. Seemingly obvious policies regarding transfer and articulation get entangled with definitions of credit, majors, general education courses, and teacher expertise. Who pays or gets paid for a dual enrollment course or who is qualified to teach advanced placement classes are just two examples where policies and values affect partnerships intended to benefit students and the community. What constitutes academic readiness and rigor is rooted in deeply held values and coming to consensus often results in difficult discussions if these values 
Crossing Boundaries: Creating Partnerships to Promote Educational Transitions

differ; whose definitions most influence the end policy is not always clear. Student maturation and the role of institutions serving as de facto parents affect how partnerships such as middle colleges are implemented. Differences in pedagogies (or andragogies), student services and support structures, counseling, student behavior policies, and other aspects of being in school are just a few of the areas of potential disconnect of policies and cultural values. Although some of these issues historically faced those few students who arrived on a college campus at an early age, their resolution was an individual matter between the student and the college. Partnership capital suggests resolving such issues are a joint responsibility of the collective, and may require creative strategies by all parties.

Policy making and institutional decision making. In general, schools are more bureaucratic in academic decision making and community colleges, more adaptive and less tied to externally imposed standards such as No Child Left Behind and various K-12 state curricular standards. In a curriculum partnership example, community college faculty have primary control over course design and content rather than being subject to state standards and federal legislation in the same way as their public school counterparts. Despite this type of control, K-14 partnerships still may hit road blocks when trying to get faculty to agree to course content, credit, and evaluation criteria. For instance, schools and community colleges often have different course numbering sequences that complicate comparability and student credits when students intermingle classes in both systems.

Community colleges are affected by the implementation of public school standards, but how changes are made in class structures and faculty development are 
decisions made by the faculty and not typically by administrators or most external agents. Conversely, most community colleges have well developed administrative infrastructures for student support services that function apart from the faculty. It may be challenging to know which college faculty and student services staff to bring together when partnering to facilitate student transitions across educational levels, whereas the public school representatives are likely more apparent and probably, fewer in number. Community College Boards of Trustees are also not the same as school boards in many ways, even when publicly elected and the institutions, publicly funded. The extent and areas of oversight vary considerably between these two governing bodies, making them more or less influential in decision making and policy development affecting partnerships. "Turf issues," on-going negotiations of credit and curricular agreements and funding arrangements, local politics and issues of constituents all affect partnership decision making.

In each of these examples, moving to a sense of shared beliefs, shared norms and processes (the partnership capital) is key to resolving organizational differences and achieving sustainable partnerships. The means to these resolutions are often not included in research on how groups come together effectively but we have found it paramount to long-term success. Including partnership capital as an aspect of collaborative development allows for a deeper analysis of the partnering process, factors that affect it, and strategies for sustaining it.

\section{Conclusions}

Nationally, community colleges and K-12 school districts collaborate with each other in creative ways that pool resources, increase student access, and achieve myriad 
educational goals for students and for the state. Cross-level collaborations can benefit each partner organization, as well as the state. Members of educational partnerships often identify shared values and goals, active participation, aligned processes, successful outcomes, mutual respect, highly focused passion, and good working relationships as reasons partnerships continue to exist. If they are mutually beneficial, achieving their desired outcomes, and important in the long-run, then leaders need to find ways to stabilize and sustain the partnerships beyond temporary funding and a single champion/leader. Generating a broader base of commitment in personnel, resources, time, and motivation are required for long-term viability.

At the same time, it is not always the case that community college partnerships can or should be maintained. They may be effective short-term strategies that address specific problems or state and local mandates, but in the long-run are not cost effective or manageable within disparate administrative structures. Partnerships may collapse, become untenable, prove unproductive or too costly, or just fade away. All the reasons for their success can quickly erode into reasons for decline and failure. And, in the end, partnerships are often difficult to establish and sustain because of fundamental differences between the educational organizations involved.

The partnership model, including the evolution of partnership capital serves as a heuristic for assessing and creating K-14 collaborations. It draws attention to critical factors that exist in the development and operation of partnerships, but that combine in different ways because of internal and external contextual circumstances. The increased call from state and federal policy makers to partner across educational systems demands better understanding of the links between formal mandates and implementation by 
Crossing Boundaries: Creating Partnerships to Promote Educational Transitions

collaborators within schools and community colleges. By understanding more fully how partnerships come together and what facilitates or challenges their longevity, it is possible to construct more effective strategic alliances between education sectors that can appropriately address a state's education and workforce learning needs. 
Crossing Boundaries: Creating Partnerships to Promote Educational Transitions

\section{References}

AACC (2009). Obama proposes historic investment to build community college capacity. July 14, 2009.

http://www.aacc.nche.edu/newsevents/pressreleases/Pages/pr07142009.aspx. downdloaded 8/7/09.

Adler, P. S., \& Kwon, S. (2000). Social capital: Prospects for a new concept. Academic of Management Review, 27(1), 17-40.

Amey, M. J. (Ed.). (2007). Collaborations across education sectors. New Directions for Community Colleges, 139. San Francisco, CA: Jossey-Bass.

Amey, M. J., \& Brown, D. F. (2004). Breaking Out of the box: Interdisciplinary collaboration and faculty work. Boston: Information Age Publishing.

Amey, M. J., Eddy, P. L., Campbell, T., \& Watson, J. (2008). The role of social capital in facilitating partnerships." Paper presented at the 2008 Council for the Study of Community College Annual Conference, Philadelphia, PA..

Amey, M. J., Eddy, P. L., \& Ozaki, C. C. Demands for partnership and collaboration in higher education: A model.” In M. J. Amey (Ed.), Collaborations Across Educational Sectors. New Directions for Community Colleges 139 (pp. 5-14). San Francisco: Jossey-Bass.

Bragg, D. D. (2000). Maximizing the benefits of tech-prep initiatives for high school students. New Directions for Community Colleges, (23), 23-30.

Bragg, D. D., \& Russman, M. L. (2007). The legislative playing field: How public policy influences collaboration. In M. J. Amey (Ed.). Collaborations Across Educational Borders. New Directions for Community Colleges 139 (pp. 93-103). San Francisco: Jossey-Bass. 
Crossing Boundaries: Creating Partnerships to Promote Educational Transitions

Bruffee, K. (1999). Collaborative learning: Higher education, interdependence, and the authority of knowledge. Baltimore: John Hopkins University Press.

Brumbach, M. A., \& Villadsen, A. W. (2002). At the Edge of Chaos: The Essentials of Resource Development for the Community College. Community College Journal of Research and Practice, 26(2), 77-86.

Bryk, A. S., \& Schneider, B. L. (2002). Trust in schools: A core resource for improvement. New York, NY: Russell Sage Foundation.

Burt, R. S. (1999). The social capital of opinion leaders. Annals of the American Academy of Political and Social Science, 566(Nov), 37-54.

Cherry Commission. (2004). Final report of the Lt. Governor's Commission on Higher Education and Economic Growth. Lansing, MI: Michigan Department of Education.

Chin, P., Bell, K. S., Munby, H., \& Hutchinson, N. L. (2004). Epistemological appropriation in one high school student's learning in cooperative education. American Educational Research Journal, 41(2), 401-417.

Chung, S., Singh, H., \& Lee, K. (2000). Complementarity, status similarity, and social capital as drivers of alliance formation. Strategic Management Journal, 21, 1-22.

Coleman, J. S. (1988). Social capital in the creation of human capital. The American Journal of Sociology, 94, S95-S120

Coleman, J. S. (1990). Foundations of social theory. Cambridge, MA: Harvard University Press.

Eddy, P. L. (2003). Sensemaking on campus: How community college presidents frame change. Community College Journal of Research and Practice, 27(6), 453-471. 
Crossing Boundaries: Creating Partnerships to Promote Educational Transitions

Eddy, P. L. (2007). Alliances among community colleges: Odd bedfellows or lasting partners? In M. J. Amey (Ed.), Collaborations Across Educational Sectors. New Directions for Community Colleges 139 (pp. 59-68). San Francisco: Jossey-Bass,.

Fairhurst, G. T., \& Sarr, R. A. (1996). The art of framing: Managing the language of leadership. San Francisco: Jossey-Bass.

Farrell, P. L., \& Seifert, K. A. Lessons learned from a dual-enrollment partnership. In M. J. Amey (Ed.), Collaborations Across Educational Sectors. New Directions for Community Colleges 139 (pp.69-77). San Francisco: Jossey-Bass.

Fear, F., Creamer, N., Pirog, R., Block, D., \& Redmond, L. (2004). Higher education community partnerships: The politics of engagement. Journal of Higher Education Outreach and Engagement, 9(2), 139-156.

Fullan, M. (2002). The change leader. Educational Leadership, 59(8), 16-20.

Frank, K. A., Zhao, Y., \& Borman, K. (2004). Social capital and the diffusion of innovations within organizations: The case of computer technology in schools. Sociology of Education, 77(2), 24.

Granovetter, M. (1983). The strength of weak ties: A network theory revisited. Sociology Theory, 1, 201-233.

Gray, B. (1989). Collaborating: Finding common ground for multiparty problems. San Francisco: Jossey-Bass.

Grubb, W. N., Badway, N., Bell, D., Bragg, D., \& Russman, M. (1997). Workforce, economic, and community development: The changing landscape of the entrepreneurial community college. Mission Viejo, CA: League for Innovation in 
Crossing Boundaries: Creating Partnerships to Promote Educational Transitions

the Community College, National Center for Research in Vocational Education, and National Council for Occupational Education.

Hart, R. (2009). Twenty community colleges in seven states join national student success initiative. Retrieved from http://www.achievingthedream.org/Portal/Modules/f62bff99-dbc8-47ef-96337be78ade27bf.asset?

Hoffman-Johnson, G. (2007). Seamless transition in the twenty-first century: Partnering to survive and thrive. In M. J. Amey (Ed.), Collaborations Across Educational Sectors. New Directions for Community Colleges 139 (pp.17-27). San Francisco: Jossey-Bass.

Hoy, W. K., \& Tschannen-Moran, M. (1999). Five faces of trust: An empirical confirmation in urban elementary schools. Journal of School Leadership, 9(3), 184-208.

Keener, B. J., Carrier, S. M., \& Meaders, S. J. (2002). Resource development in community colleges: A national overview. Community College Journal of Research and Practice, 26(1), 7-23.

Keller, G. (2008). Why college should offer 3-year diplomas. The Chronicle of Higher Education, 55(12), A42.

Kisker, C. B., \& Hauser, P. (2007). Partnering to move students into college and community-oriented careers: The administration of justice department at East Los Angeles College. In M. J. Amey (Ed.), Collaborations Across Educational Sectors. New Directions for Community Colleges 139 (pp.29-39). San Francisco: Jossey-Bass. 
Crossing Boundaries: Creating Partnerships to Promote Educational Transitions

Kotter, J. P. (1996). Leading change. Boston: Harvard Business School Press.

Kotter, J. P., \& Cohen, D. S. (2002). The heart of change: Real-life stories of how people change their organizations. Cambridge, MA: Harvard Business School Press.

Levin, J. S. (2002). Global culture and the community college. Community College Journal of Research and Practice, 26(2), 121-145.

Lincoln, C. (2009, January-February). Courageous conversations: Achieving the dream and the importance of student. Change Magazine. Retrieved from http://www.changemag.org/Archives/Back\%20Issues/JanuaryFebruary\%202009/full-achieving-dream.html

Lumina Foundation. (2009). A stronger nation through higher education: How and why Americans must meet a "big goal” for college attainment. Indianapolis, IN: Lumina Foundation for Education.

Morgan, G. (1998). Images of organization (2 ${ }^{\text {nd }}$ ed.). Thousand Oaks, CA: Sage Publication.

Rasch, E. (2002). The influence of state policies on community college dual credit programs. Unpublished working paper, Office of Community College Research and Leadership, University of Illinois at Urbana-Champaign.

Russman, M. A. (2001). Community college and one-stop center collaboration: The role of community college collaborative agents. Unpublished doctoral dissertation, University of Illinois at Urbana-Champaign.

Russell, J. F., \& Flynn, R. B. (2000). Commonalities across effective collaboratives. Peabody Journal of Education, 75(3), 196-204. 
Crossing Boundaries: Creating Partnerships to Promote Educational Transitions

Scott, W. R. (2003). Organizations: Rational, natural, and open systems. Upper Saddle River, NJ: Prentice Hall.

Sheer, M. D., \& de Vise, D. (2009, July 15). Obama announces community college plan: $\$ 12$ billion will fund new web courses, construction and innovation grants. Washington Post. Retrieved from http://www.washingtonpost.com/wpdyn/content/article/2009/07/14/AR2009071400819.html?sid=ST2009071502758

Sink, D. W., Jackson, K. L., Boham, K. A., \& Shockley, D. (2004). The Western North Carolina Technology Consortium: A collaborative aproach to bridging the digital divide. Community College Journal of Research and Practice, 28(4), 321-329.

Smyth, J. (1989). A 'pedagogical' and 'educative' view of leadership.” In J. Smyth, (Ed.) Critical Perspectives on Educational Leadership (pp. 179-204). New York: The Falmer Press.

Todeva, E., \& Knoke, D. (2005). Strategic alliances and models of collaboration.” Management Decision, 43(1), 123-148.

Watson, J. S. (2007). Stepping outside the big box high school: A partnership influenced by goals, capital, and decision making. In M. J. Amey (Ed.), Collaborations Across Educational Sectors. New Directions for Community Colleges 139 (pp.4957). San Francisco: Jossey-Bass.

Weick, K. E. (2001). Leadership as the legitimation of doubt. In W. Bennis, G. M. Spreitzer, \& T. G. Cummings (Eds.), The Future of Leadership: Today's Top Leadership Thinkers Speak to Tomorrow's Leaders (pp. 91-102). San Francisco: Jossey-Bass.

Weick, K. E. (1995). Sensemaking in Organizations. Thousand Oaks, CA: Sage. 
Crossing Boundaries: Creating Partnerships to Promote Educational Transitions 


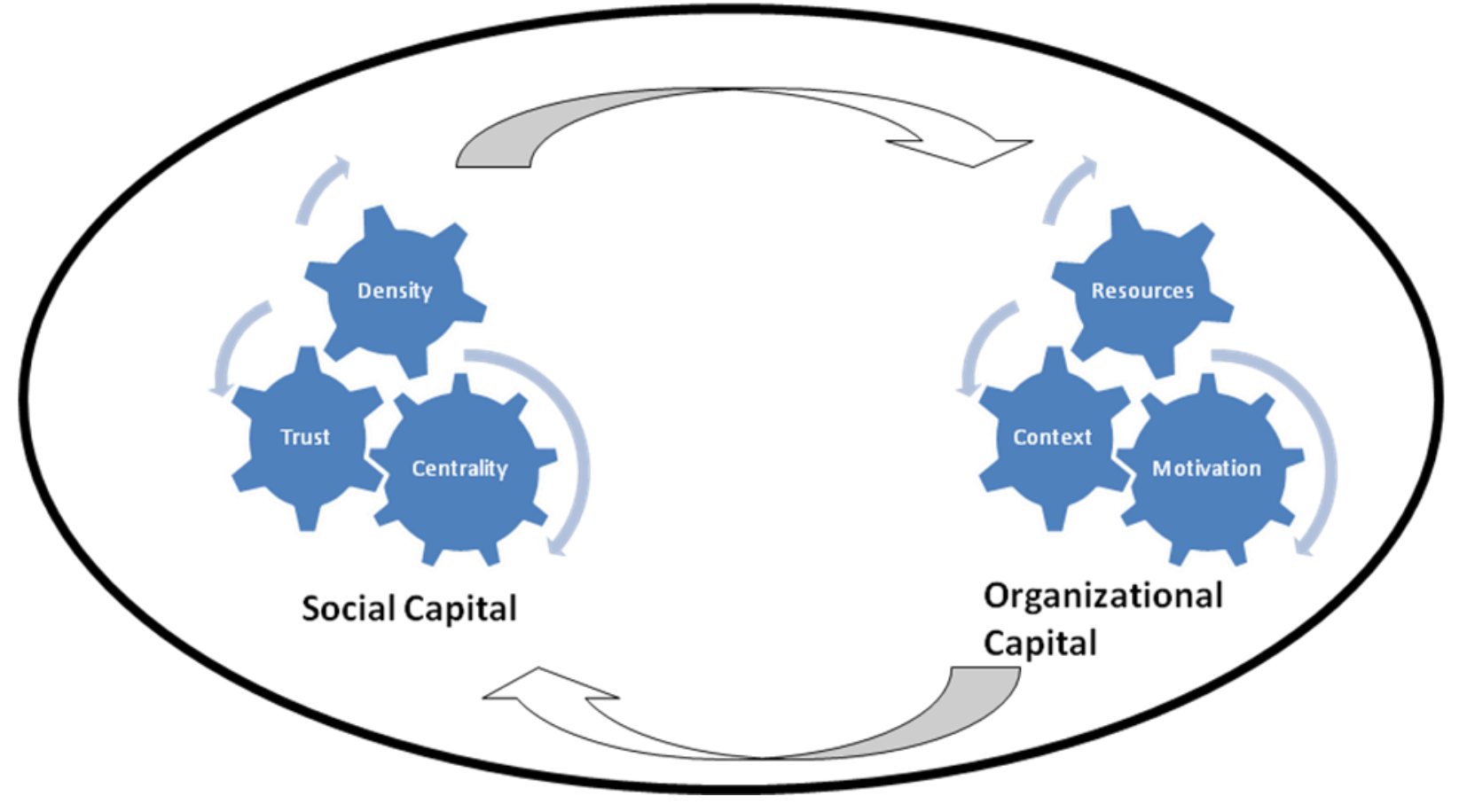

Figure 1. Partnership Antecedents 


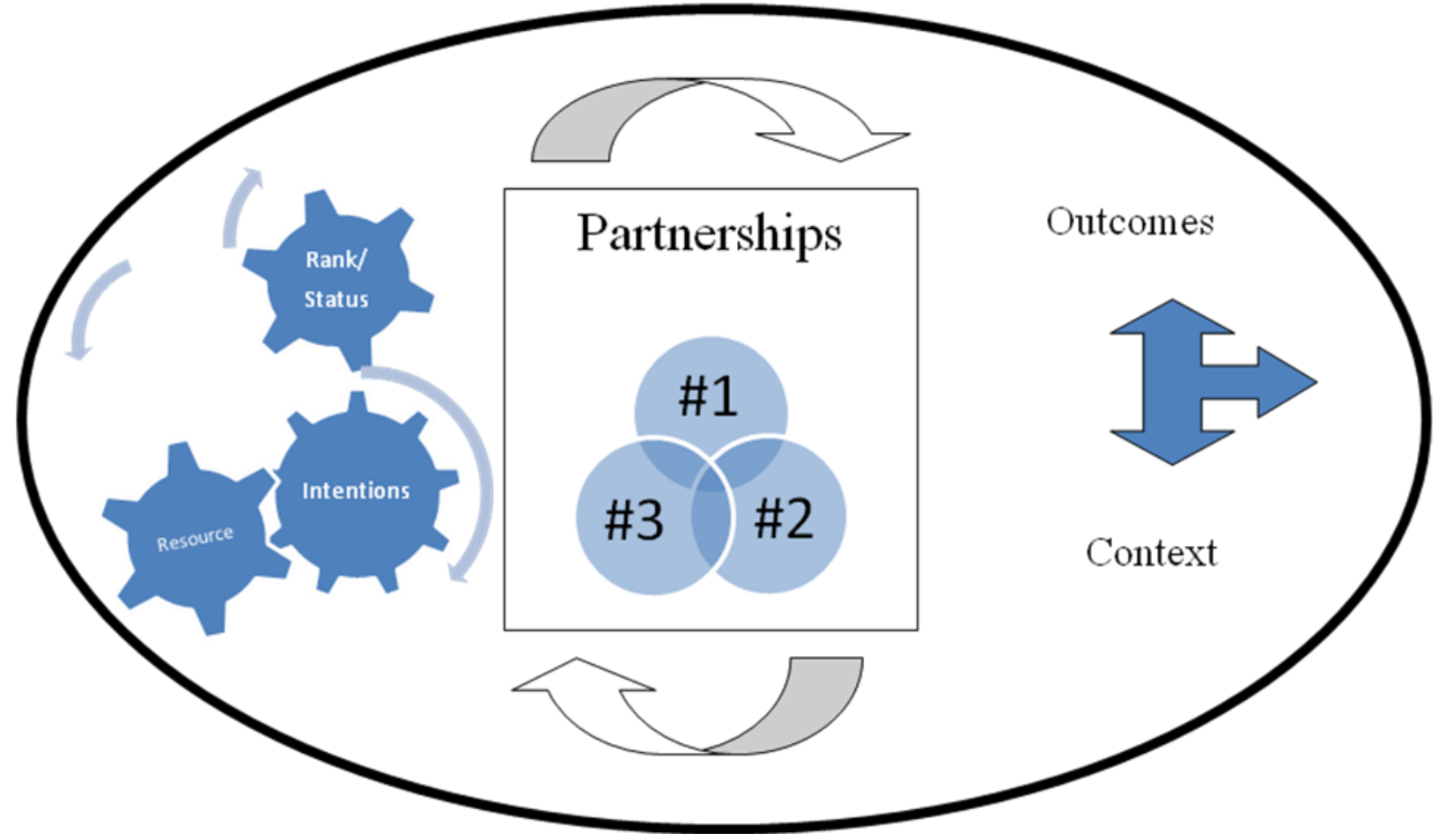

Figure 2. Partnership Development 


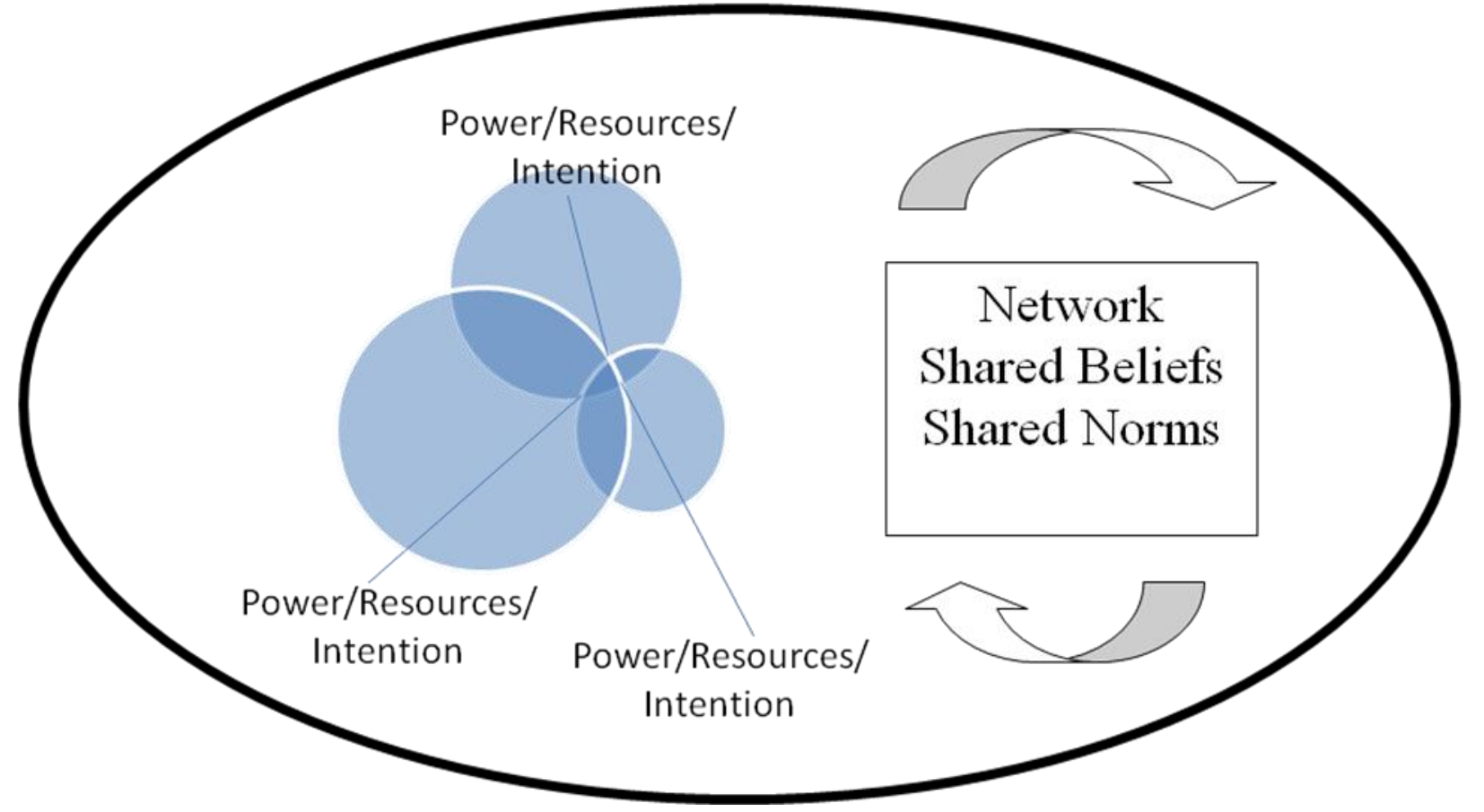

Figure 3. Partnership Capital 